\title{
Is the routine placement of a feeding jejunostomy during esophagectomy worthwhile? - a systematic review and meta-analysis
}

\author{
Xu Shen ${ }^{1 \#}$, Ze-Guo Zhuo ${ }^{1 \#}$, Gang Li ${ }^{2}$, Gu-Ha Alai ${ }^{1}$, Tie-Niu Song ${ }^{1}$, Zhi-Jie Xu' ${ }^{1}$, Peng Yao ${ }^{1}$, Yi-Dan Lin ${ }^{1}$ \\ ${ }^{1}$ Department of Thoracic Surgery, West China Hospital, Sichuan University, Chengdu, China; ${ }^{2}$ Department of Thoracic Surgery, Hospital of \\ Chengdu Office of People's Government of Tibetan Autonomous Region, Chengdu, China \\ Contributions: (I) Conception and design: YD Lin, ZG Zhuo, X Shen; (II) Administrative support: YD Lin; (III) Provision of study materials or \\ patients: YD Lin, ZG Zhuo, X Shen; (IV) Collection and assembly of data: X Shen, ZG Zhuo, G Li, GH Alai, TN Song, ZJ Xu, P Yao; (V) Data \\ analysis and interpretation: X Shen, ZG Zhuo, G Li, GH Alai, TN Song, ZJ Xu, P Yao; (VI) Manuscript writing: All authors; (VII) Final approval of \\ manuscript: All authors. \\ "These authors contributed equally to this work. \\ Correspondence to: Yi-Dan Lin. Department of Thoracic Surgery, West China Hospital, Sichuan University, 37 Guoxue Alley, Chengdu 610041, \\ China. Email: linyidan.academy@foxmail.com.
}

\begin{abstract}
Background: Malnutrition dramatically increases the risk of postoperative complications and delays patient recovery. Therefore, a feeding jejunostomy tube (FJT) is routinely placed during esophagectomy to maintain the postoperative nutrition supply. However, recently published studies have questioned the need of a FJT in every esophageal cancer patient. Because most patients can resume oral intake shortly after surgery, the nutrition-providing function of a FJT becomes much less critical. In contrast, FJT-related complications could be severe.
\end{abstract}

Methods: Relevant publications were found out by systemic searching of four medical databases (PubMed, EMBASE, Medline, and Cochrane Center Register of Controlled Trials). By reading the titles and the abstracts, potentially relevant studies were screened from the search results. The incidence of postoperative complications and FJT-related complications were calculated and compared to evaluate the efficacy of a FJT.

Results: Eighteen studies were included in the meta-analysis. The no-FJT group had a similar or even lower incidence of postoperative complications [anastomotic leakage (AL), pulmonary complications, and wound infections] compared with the FJT group. Ileus and FJT site infections were the most common FJTrelated complications. The incidence of ileus was approximately 6\% (95\% CI: $3-12 \%$ ), and over $63 \%$ of the patients with an ileus required re-operation to relieve the obstruction. The pooled mean rate of FJT site infections was 7\% (95\% CI: 6-9\%). Approximately 7\% of patients had dysfunction (obstruction or dislocation) of the jejunostomy tube (95\% CI: 3-14\%).

Conclusions: The non-selective placement of a FJT during esophagectomy provides few benefits to the patients and may even increase the risk of postoperative complications. Therefore, an intraoperative FJT should be selectively prescribed, but not routinely in the surgical treatment of esophageal cancer.

Keywords: Esophagectomy; enteral nutrition; jejunostomy; meta-analysis

Submitted Dec 16, 2020. Accepted for publication Feb 24, 2021.

doi: 10.21037/apm-20-2519

View this article at: http://dx.doi.org/10.21037/apm-20-2519 


\section{Introduction}

Surgery with or without neoadjuvant therapy is now the standard treatment for locally advanced esophageal cancer (1). However, the surgical procedure is highly invasive, involving the abdomen, thorax, and even the neck. Moreover, malnutrition is common in patients with esophageal cancer (2). Malnutrition dramatically increases the risk of postoperative complications and delays patient recovery (3). Therefore, a feeding jejunostomy tube (FJT) is routinely placed during surgery to ensure adequate postoperative nutrition.

Recent studies have questioned the need for a FJT in all esophageal cancer patients (4-6). Because most patients resume oral intake shortly after surgery, providing nutrition via a FJT is not critical. In contrast, FJT-related complications, such as ileus and jejunum perforation, can be severe $(7,8)$. Therefore, these studies recommend selective placement of a FJT during esophagectomy.

We compared the postoperative outcomes between patients with and without a FJT to evaluate the need for a FJT in every patient, and calculated the incidence of FJT-related complications to assess the safety of FJT. In addition, the characteristics of patients who benefited from a FJT were summarized.

We present the following article in accordance with the PRISMA reporting checklist (available at http://dx.doi. org/10.21037/apm-20-2519).

\section{Methods}

The study was designed according to the PRISMA (Preferred Reporting Items for Systematic Reviews and Meta-analyses) statement. The online searching of four medical databases (PubMed, EMBASE, Medline, and Cochrane Center Register of Controlled Trials) were performed on 18 November 2019. The searching was conducted basing on the following terms: (enteral nutrition OR jejunostomy OR nasogastric feeding OR nasoduodenal OR nasojejunostomy OR nasojejunal) AND (esophagectomy OR oesophagectomy OR esophagus OR esophageal OR oesophagus OR oesophageal) AND (tumor OR tumour OR cancer OR carcinoma OR neoplasm).

\section{Inclusion and exclusion criteria}

The inclusion criteria were as follows: (I) studies that enrolled patients who underwent esophagectomies for esophageal cancer; and (II) studies that compared the postoperative outcomes between patients who did and did not have an FJT placed intraoperatively.

The exclusion criteria were as follows: (I) non-English publications; (II) reviews, meta-analyses, study protocols, case reports, abstracts presented at a conference, comments, and replies; and (III) in the case of duplicate data, the study with the smaller sample size.

\section{Study screening and quality assessment}

By reading the titles and abstracts, irrelevant studies were removed. Then, the full texts of the selected studies were carefully read and the data of targeted outcomes were extracted to confirm the eligibility of the included studies. According to the MINORS (Methodological Index for Non-Randomized Studies) score, the quality of included studies was assessed. Study selection and data extraction were independently performed by two authors (Shen and Zhuo); disagreements were resolved by discussion with a third author (Lin).

\section{Statistical analysis}

The odds ratio (OR) was used to compare dichotomous data. $\mathrm{I}^{2}$ was used as an indicator of heterogeneity. Specifically, $\mathrm{I}^{2}<25 \%, 25 \% \leq \mathrm{I}^{2}<50 \%$, and $\mathrm{I}^{2} \geq 50 \%$ indicated low, moderate, and high heterogeneity, respectively. A random-effects model would be adopted when high heterogeneity was detected, otherwise, a fixed-effects model was adopted. Publication bias was evaluated by Begg's and Egger's tests. The difference was considered statistically significant when the p-value was less than 0.05 . All the data analyses were performed by RevMan 5.3 software and STATA (version 12.0; Stata Corporation, College Station, TX, USA).

\section{Results}

The online database search identified 3,029 potentially relevant studies. After removing 1,276 duplicate studies, 1,753 studies entered the first round of screening, during which the titles and abstracts were read. Of the 1,753 studies, 26 were in vitro or animal studies, 755 were ineligible publication types, and the targeted intervention of 928 did not satisfy the aim of our study. Thus, 44 highly-relevant studies remained for further evaluation. By reading the full texts of the 44 studies, three conference abstracts, 10 non-English publications, and 


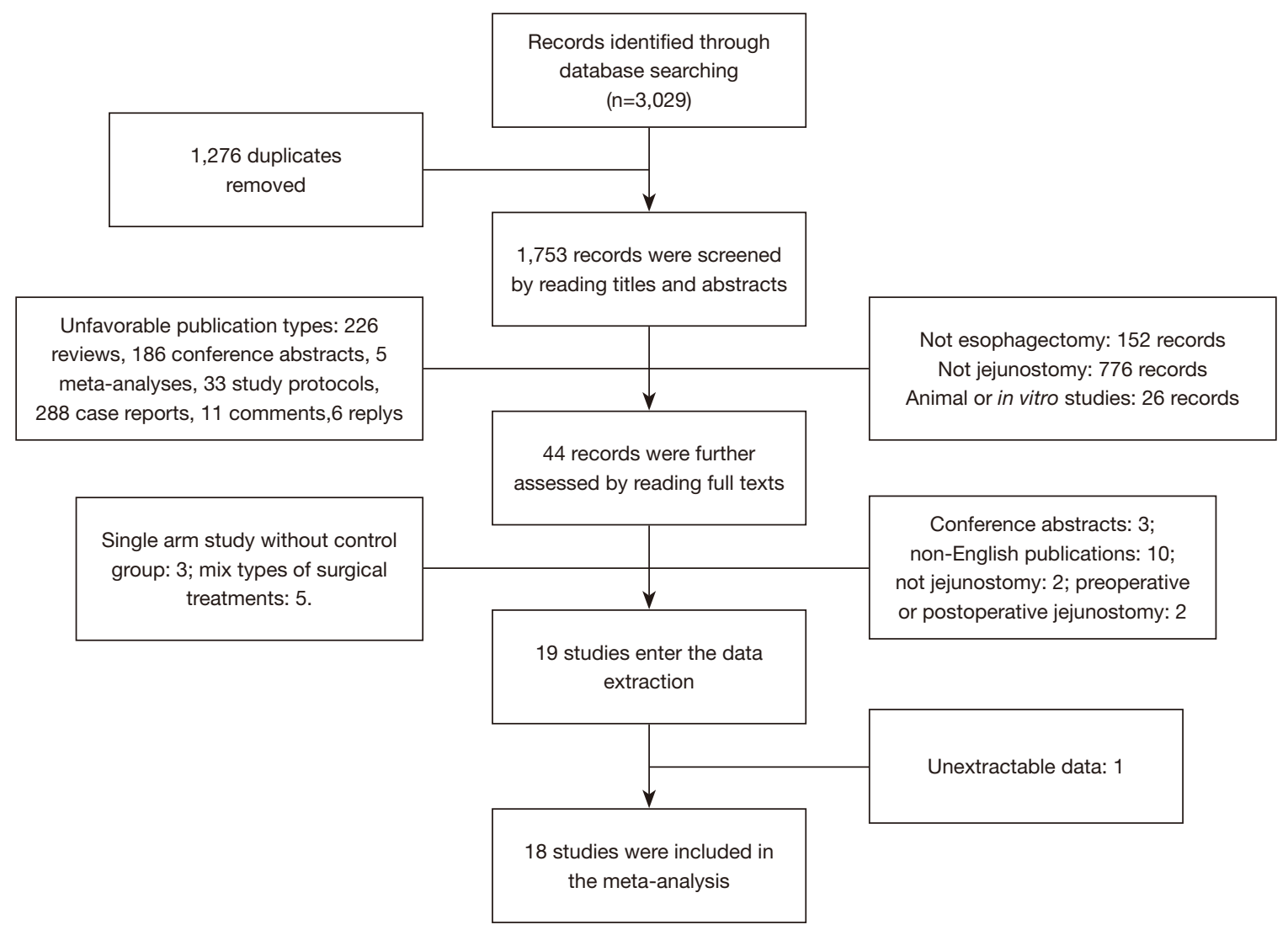

Figure 1 The screening procedures of the studies included in the meta-analysis.

eight studies with disqualifying interventions were excluded. Three single-arm studies (9-11) without controls were also excluded. Nineteen studies met the inclusion criteria for this meta-analysis, thus, data extraction was performed. The target outcomes of one study (12) could not be extracted, therefore, 18 studies $(4-8,13-25)$ were included in the final analysis. The details of the study selection procedures are shown in Figure 1, and Table 1 shows the base line characteristics of the studies included in the meta-analysis.

\section{Postoperative complications}

Sixteen studies reported the incidence of anastomotic leakage (AL). The overall prevalence of AL in the feeding jejunostomy tube group (FJT-G) was $10.04 \%$ and $8.48 \%$ in the no feeding jejunostomy tube group (no FJT-G). The rate of AL was quite close between the two groups, but the pooled analysis indicated a statistically significant difference ( $\mathrm{OR}=1.27,95 \%$ CI: 1.02-1.59, $\mathrm{P}=0.03$; Figure $2 A$ ). The no FJT-G also had a significantly lower incidence of pulmonary complications
$(\mathrm{OR}=1.24,95 \% \mathrm{CI}: 1.01-1.51, \mathrm{P}=0.04$; Figure $2 B)$. Ten studies were included in the comparison of postoperative ileus. The FJT-G had a higher incidence of ileus. The overall rates of ileus in the FJT-G and no FJT-G were $5.87 \%$ and $0.74 \%$, respectively. The meta-analysis showed a statistically significant difference in the occurrence of ileus $(\mathrm{OR}=7.49$, 95\% CI: 3.78-14.85, $\mathrm{P}<0.001$; Figure 2C). The FJT-G also had a higher incidence of wound infections (7.00\% vs. 3.74\%) and the difference was statistically significant $(\mathrm{OR}=2.01,95 \%$ CI: 1.46-2.75, P<0.001; Figure 2D). The FJT-G and no FJT-G had a similar prevalence of chyle $(3.16 \%$ vs. $3.82 \%$; OR $=0.89$, 95\% CI: 0.51-1.55, P=0.67).

\section{fejunostomy-related complications}

Ileus and jejunostomy site infections were the most frequent jejunostomy-related complications. The overall mean jejunostomy-related ileus rate was 6\% (95\% CI: 3-12\%; Figure $3 A$ ). Among the 33 patients who had an ileus, 21 $(63.64 \%)$ required re-operation to relieve the obstruction. 
Table 1 The baseline characteristics of the studies included in the meta-analysis

\begin{tabular}{|c|c|c|c|c|c|c|}
\hline Study & Design & $\begin{array}{l}\text { Sample size } \\
\text { (FJT:no FJT) }\end{array}$ & $\begin{array}{l}\text { Surgery } \\
\text { type }\end{array}$ & $\begin{array}{l}\text { FJG nutrition } \\
\text { intervention }\end{array}$ & $\begin{array}{l}\text { NFJG nutrition } \\
\text { intervention }\end{array}$ & $\begin{array}{l}\text { MINORS } \\
\text { score }\end{array}$ \\
\hline Kroese 2019 & $\mathrm{R}$ & $135: 53$ & MIE & EN through FJT, OI on the $5^{\text {th }} \mathrm{POD}$ & Ol on the $5^{\text {th }} P O D$ & 11 \\
\hline Álvarez-Sarrado 2019 & $\mathrm{R}$ & $47: 53$ & NA & EN through FJT & $\mathrm{PN}$ & 11 \\
\hline Akiyama 2018 & $\mathrm{R}$ & $33: 43$ & MIE or OE & EN through FJT, PN, OI on $6-7^{\text {th }}$ POD & $\mathrm{PN}, \mathrm{Ol}$ on the $6-7^{\text {th }} \mathrm{POD}$ & 12 \\
\hline Scarpa 2014 & $\mathrm{R}$ & 40:69 & OE & EN through FJT & NA & 11 \\
\hline Huang 2014 & $\mathrm{R}$ & 153:121 & NA & EN through FJT, OI on the $5^{\text {th }} \mathrm{POD}$ & $\begin{array}{l}\text { EN through gastrostomy, } \\
\text { OI on the } 5^{\text {th }} \text { POD }\end{array}$ & 11 \\
\hline Konishi 2018 & $\mathrm{R}$ & $82: 133$ & NA & EN through $\mathrm{FJT}$, OI on the $7^{\text {th }} \mathrm{POD}$ & $\begin{array}{l}\text { EN through gastrostomy, } \\
\text { Ol on the } 7^{\text {th }} \text { POD }\end{array}$ & 11 \\
\hline Arif 2018 & $\mathrm{P}$ & $162: 163$ & OE & EN through FJT & NA & 13 \\
\hline Kawai 2017 & $\mathrm{R}$ & 214:206 & $\mathrm{OE}$ & EN through FJT, OI on the $8^{\text {th }} \mathrm{POD}$ & $\begin{array}{l}\text { EN through gastrostomy, } \\
\text { Ol on the } 8^{\text {th }} \text { POD }\end{array}$ & 12 \\
\hline Elshaer 2016 & $\mathrm{R}$ & $14: 41$ & MIE or OE & EN through FJT & EN through NJT & 11 \\
\hline Takesue 2015 & $\mathrm{P}$ & $24: 23$ & MIE & EN through FJT, OI on the $8^{\text {th }}$ POD & $\mathrm{PN}, \mathrm{Ol}$ on the $8^{\text {th }} \mathrm{POD}$ & 15 \\
\hline Rajabi Mashhadi 2015 & $\mathrm{P}$ & $20: 20$ & NA & EN through FJT, OI on the $7^{\text {th }}$ POD & $\mathrm{PN}, \mathrm{Ol}$ on the $7^{\text {th }} \mathrm{POD}$ & 13 \\
\hline Oya 2015 & $\mathrm{R}$ & $267: 111$ & NA & EN through FJT, OI on the $7^{\text {th }}$ POD & $\begin{array}{l}\text { EN through duodenostomy, } \\
\text { OI on the } 7^{\text {th }} \text { POD }\end{array}$ & 11 \\
\hline
\end{tabular}

$\mathrm{R}$, retrospective; P, prospective; NA, not available; MIE, minimal invasive esophagectomy; OE, open esophagectomy; EN, enteral nutrition; PN, parenteral nutrition; OI, oral intake; POD, postoperative day; FJT, feeding jejunostomy tube; MINORS, Methodological Index for Non-Randomized Studies.

Eight studies were included in the analysis of jejunostomy site infections and the mean pooled rate was 7\% (95\% CI: $6-9 \%$; Figure 3B). Approximately $7 \%$ of patients had obstruction or dislocation of the jejunostomy tube (95\% CI: $3-14 \%$; Figure 3C). The details of the jejunostomy-related complications data are summarized in Table 2.

\section{Indications for intraoperative placement of a FFT}

Among the included studies, seven selected patients who were recommended to have the intraoperative placement of a FJT. The recommendations are summarized in Table 3. Patients at high risk for postoperative complications (AL and pulmonary complications) were widely recommended to have the intraoperative placement of a FJT. The nutritional status was also considered. The body mass index (BMI), NRS-2002 screening test, and severe preoperative dysphagia were included in evaluating patient nutrition status. Patients undergoing open surgery or a McKeown esophagectomy were also candidates for a FJT due to the greater extent of surgical trauma. The decision for intraoperative placement of a FJT was also made based on the patient's condition during surgery. Specifically, placement of a FJT was considered in the case of an intraoperative bilateral vocal code palsy or a depressed bloodstream of conduit. Older age and neoadjuvant therapy were also indications for an 

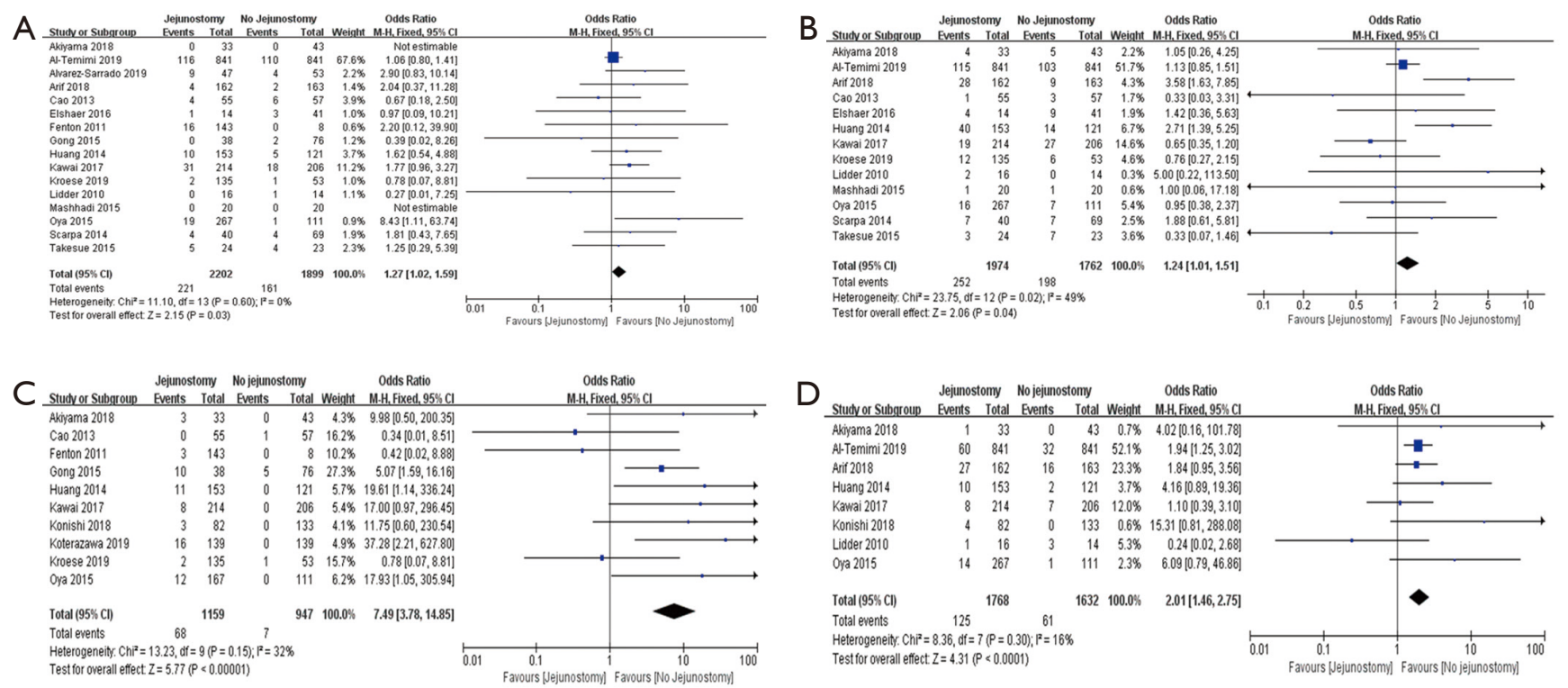

Figure 2 The comparison of postoperative complication between JG and NJG. (A) JG had a significantly higher incidence of anastomotic leakage than NJG [OR $=1.27,95 \%$ CI: 1.02 to $1.59 ; \mathrm{P}=0.03$ ). (B) JG had a significantly higher incidence of pulmonary complications than NJG (OR $=1.24,95 \% \mathrm{CI}: 1.01$ to $1.51 ; \mathrm{P}=0.04)$. (C) JG had a significantly higher incidence of ileus than NJG (OR $=7.49,95 \% \mathrm{CI}: 3.78$ to 14.85; $\mathrm{P}<0.001)$. (D) JG had a significantly higher incidence of wound infection than NJG ( $\mathrm{OR}=2.01,95 \% \mathrm{CI}: 1.46$ to $2.75 ; \mathrm{P}<0.001)$.

intraoperative FJT.

\section{Publication bias and beterogeneity}

All meta-analyses had low or moderate heterogeneity except the single-arm analysis of jejunostomy-related complications. Therefore, the random effect model was adopted in these analyses. The Begg's $(\mathrm{P}=0.381$; Figure $4 A)$ and Egger's tests $(\mathrm{P}=0.382$; Figure $4 B)$ indicated no publication bias.

\section{Discussion}

Our study showed that the routine intraoperative placement of a FJT did not decrease the incidence of postoperative complications in esophageal cancer. The analyses indicated that patients who received an intraoperative FJT had a significantly higher risk of postoperative complications than patients who did not receive an intraoperative FJT. Moreover, an intraoperative FJT may lead to severe jejunostomy-related complications that require surgery. Therefore, an intraoperative FJT should be selectively, not routinely prescribed in the surgical treatment of esophageal cancer.
The perioperative nutritional status is associated with the rehabilitation and prognosis of esophageal cancer patients $(26,27)$. Malnutrition may increase the risk of postoperative complications $(13,28)$. The studies conducted by ÁlvarezSarrado et al. (4) and Akiyama et al. (5) demonstrated that the total protein and albumin levels were similar between the FTJ-G and no FTJ-G on postoperative day 7. The changes in body weight or BMI 1, 3, and 6 months after surgery were also comparable between the FJT-G and no FJT-G $(5,6,13)$. These results indicated that the postoperative nutrition status of patients in the FJT-G and no FJT-G was similar. The Kroese et al. (13) reported that only 4 patients $(7.5 \%)$ in the no FJT-G needed a FJT after surgery and only 1 patient $(0.7 \%)$ in the no FJT-G received a FJT postoperatively in the study conducted by Koterazawa et al. (6). Therefore, these surgeons were of the opinion that the intraoperative placement of a FJT is not necessary for every patient, especially patients without severe complications.

The non-selective placement of a FJT has limited benefits to the patient and may even increase the risk of postoperative complications. Scarpa et al. (15) reported comparable postoperative outcomes between the FJT-G and no FJT-G; however, Al-Temimi et al. (7) and Arif et al. (8) 


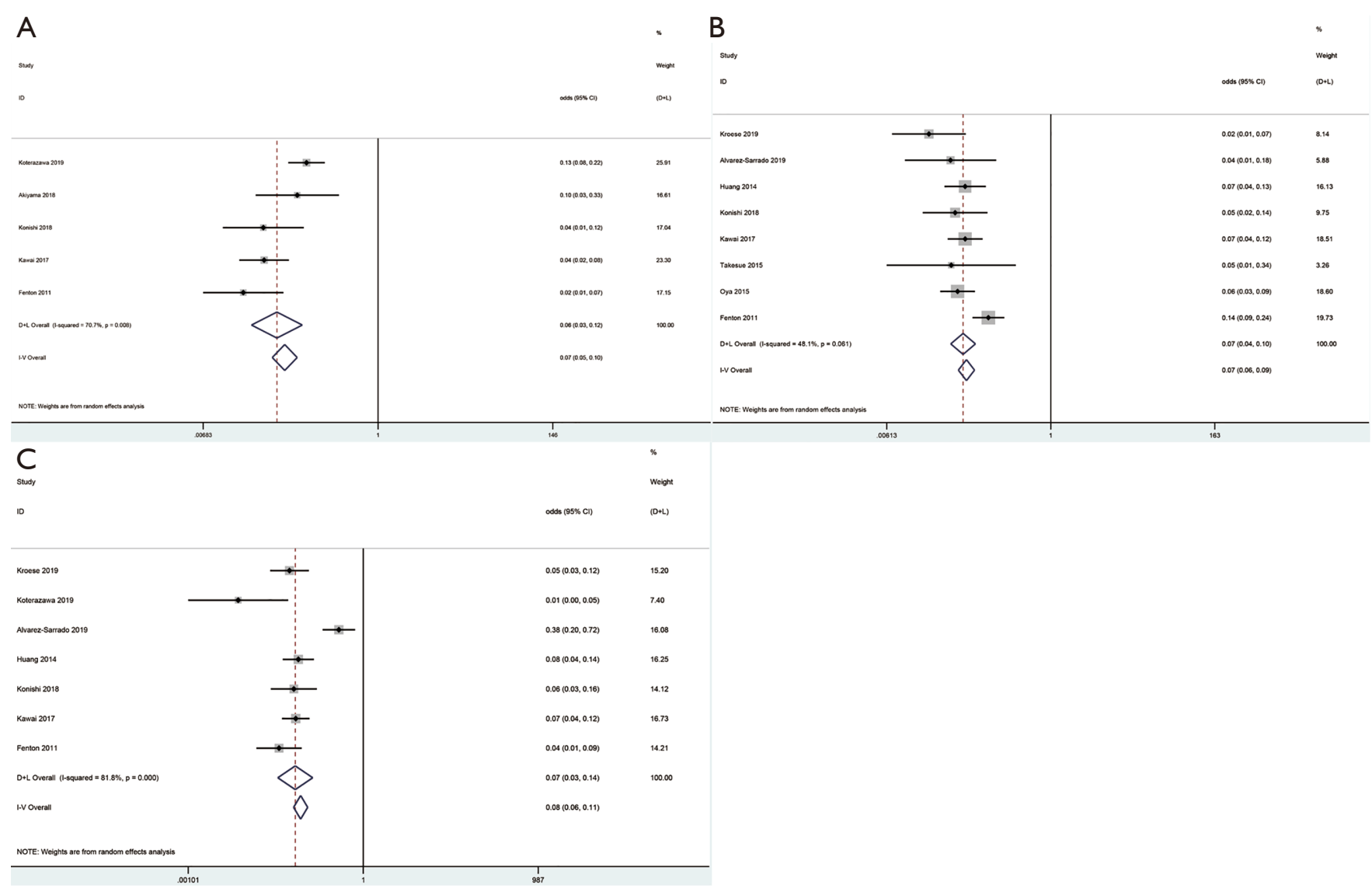

Figure 3 The single-arm analysis of the jejunostomy-related complications. (A) The mean incidence of jejunostomy-related was $6 \%$ (95\% CI: 3-12\%). (B) The mean incidence of jejunostomy site infection was 7\% (95\% CI: 6-9\%). (C) The mean incidence of jejunostomy dysfunction was $7 \%$ (95\% CI: 3-14\%).

revealed a higher incidence of morbidities in patients who received a FJT. Although a statistically significant difference was detected in our meta-analysis, the overall rate of $\mathrm{AL}$ and pulmonary complications was very close between the two groups. The overall AL rate was $8.5 \%$ in the no FJT-G and $10.0 \%$ in the FJT-G. The incidence of pulmonary complications was $11.2 \%$ in the no FJT-G and $12.9 \%$ in the FJT-G. The incidence of complications in the two groups was close; however, the statistically significant difference is unlikely to be clinically meaningful. Therefore, we believe the incidence of AL and pulmonary complications are comparable between the two groups. The FJT-related complications are the most important reason why we recommend that the FJT should be prescribed selectively, but not routinely. The FJT-related complications included ileus, infection of the jejunostomy site, and obstruction or dislocation of the FJT. Between $10 \%$ and $40 \%$ of patients have a FJT-related complication and between $2 \%$ and $15 \%$ have a severe FJT-related complication $(7,13)$. From the perspective of the patient, the FJT is the complication.

In fact, a FJT is not always unhelpful. A FJT plays a vital role in the recovery of patients who have severe postoperative complications, such as an AL and a pulmonary infection $(6,7)$. Koterazawa et al. (6) reported that age ( $>75$ years), neoadjuvant therapy, AL, and pulmonary complications are independent risk factors for long-term FJT placement. Thus, Koterazawa et al. (6) recommended that older patients or patients at high risk for postoperative complications are candidates for the intraoperative placement of a FJT. For patients who resume oral intake early, the function of a FJT is not quite as important (29). The FJT may even affect the patient's emotions and decrease the quality of life. Scarpa et al. (15) reported that patients who received a FJT had poor emotional function compared 
Table 2 The detail data of jejunostomy-related complications in each study

\begin{tabular}{|c|c|c|c|}
\hline Study & $\begin{array}{l}\text { Jejunostomy-related } \\
\text { complications }\end{array}$ & $\begin{array}{l}\text { The overall rate of } \\
\text { Jejunostomy-related complications }\end{array}$ & $\begin{array}{l}\text { The overall rate of reoperation for } \\
\text { Jejunostomy-related complications }\end{array}$ \\
\hline Kroese 2019 & $\begin{array}{l}\text { Wound infection: } 3 / 135 ; \\
\text { jejunostomy dysfunction: 15/135 }\end{array}$ & $18 / 135(13.33 \%)$ & $2 / 18(11.11 \%)$ \\
\hline Koterazawa 2020 & $\begin{array}{l}\text { lleus: } 16 / 139 \text {; } \\
\text { jejunostomy dysfunction: 1/139 }\end{array}$ & $17 / 139(12.23 \%)$ & $13 / 17(76.47)$ \\
\hline Akiyama 2018 & Ileus: $3 / 33$ & $3 / 33(9.09 \%)$ & $3 / 3(100 \%)$ \\
\hline Huang 2014 & $\begin{array}{l}\text { Wound infection: } 10 / 153 ; \\
\text { jejunostomy dysfunction: } 11 / 153\end{array}$ & $21 / 153(13.73 \%)$ & NR \\
\hline Takesue 2015 & lleus: 0/23; wound infection: 1/23 & $1 / 23(4.35 \%)$ & NR \\
\hline Oya 2015 & Wound infection: $14 / 267$ & $14 / 267(5.24 \%)$ & NR \\
\hline Fenton 2011 & $\begin{array}{l}\text { lleus: } 3 / 143 \text {; wound infection: } 18 / 143 \text {; } \\
\text { jejunostomy dysfunction: } 5 / 143\end{array}$ & 26/143 (18.18\%) & $0 / 26(0 \%)$ \\
\hline
\end{tabular}

NR, not reported.

Table 3 Indications for intraoperative placement of feeding jejunostomy tube from included studies

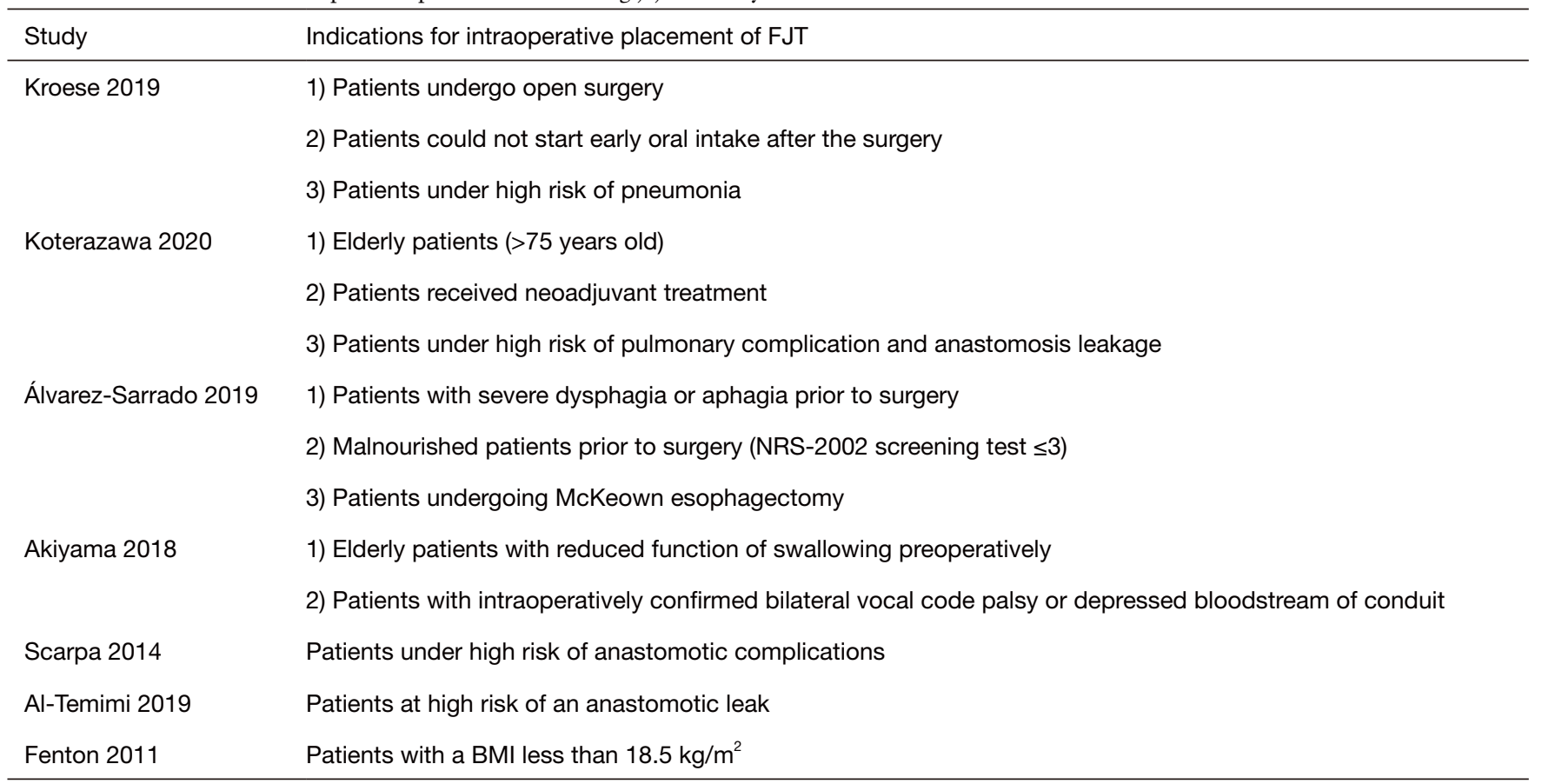

FJT, feeding jejunostomy tube; BMI, Body mass index; NRS 2002, Nutritional risk screening 2002. 

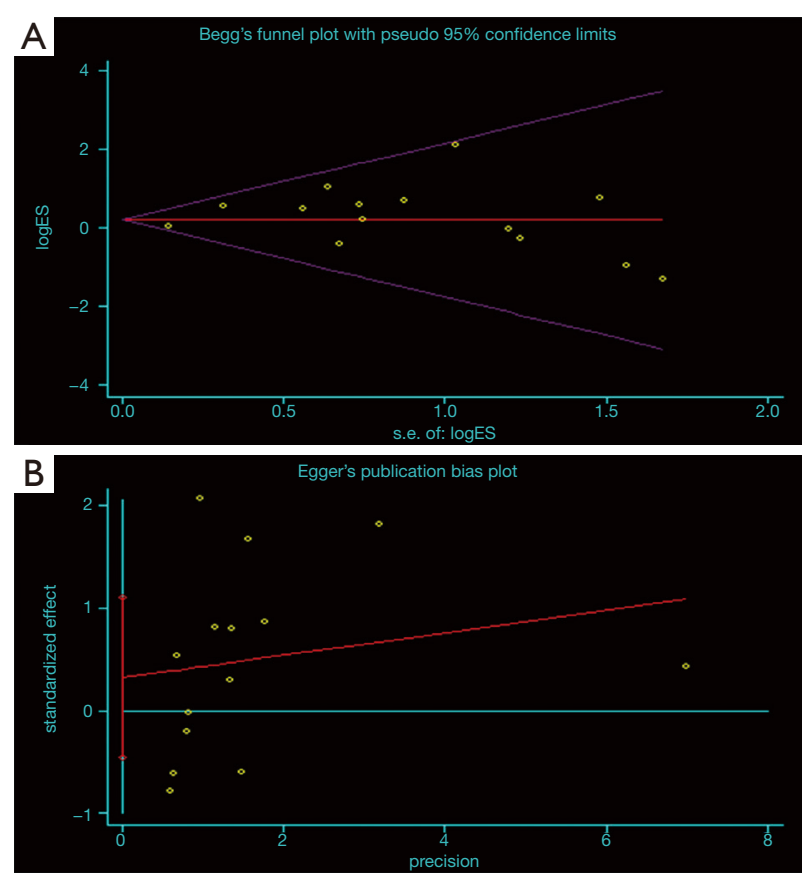

Figure 4 Begg's and Egger's test for the detection of publication bias. Both the Begg's $(\mathrm{P}=0.381)$ and Egger's test $(\mathrm{P}=0.382)$ detected no publication bias.

to patients who did not receive a FJT.

We summarized the indications for intraoperative placement of a FJT from included studies. The risk for postoperative complications, age, nutritional status, surgery type, intraoperative conditions, and neoadjuvant therapy should be taken into consideration when deciding if a FJT is placed during surgery.

Our meta-analysis had some limitations. First, the reported FJT-related complication rate varied among the studies, so a single-arm analysis of FJT-related complications had high heterogeneity. The single-arm analysis was thought to provide a rough evaluation of the rate of FJTrelated complications. Despite high heterogeneity, the metaanalysis provided the data we sought. Second, postoperative nutritional supplementation in the no FJT-G also varied among the included studies, and decreased the level of evidence in the meta-analysis. Finally, if the FJT affected long-term survival or long-term nutrition status was not analyzed in our study due to limited data.

Nevertheless, our study indicated that the intraoperative placement of a FJT was not suitable and beneficial for every esophageal cancer patient. A FJT should be prescribed selectively, but not routinely. How to accuratelyidentify the patients who need a FJT will be the focus of corollary studies.

\section{Acknowledgments}

We thank International Science Editing (http//www. internationalscienceediting.com) for editing this manuscript. Funding: This work was supported by the National Natural Science Foundation of China (grant number: 81672291, 31071210 to YD Lin).

\section{Footnote}

Reporting Checklist: The authors have completed the PRISMA reporting checklist. Available at http://dx.doi. org/10.21037/apm-20-2519

Conflicts of Interest: All authors have completed the ICMJE uniform disclosure form (available at http://dx.doi. org/10.21037/apm-20-2519). The authors have no conflicts of interest to declare.

Ethical Statement: The authors are accountable for all aspects of the work in ensuring that questions related to the accuracy or integrity of any part of the work are appropriately investigated and resolved.

Open Access Statement: This is an Open Access article distributed in accordance with the Creative Commons Attribution-NonCommercial-NoDerivs 4.0 International License (CC BY-NC-ND 4.0), which permits the noncommercial replication and distribution of the article with the strict proviso that no changes or edits are made and the original work is properly cited (including links to both the formal publication through the relevant DOI and the license). See: https://creativecommons.org/licenses/by-nc-nd/4.0/.

\section{References}

1. Ajani JA, D'Amico TA, Bentrem DJ, et al. Esophageal and Esophagogastric Junction Cancers, Version 2.2019, NCCN Clinical Practice Guidelines in Oncology. J Natl Compr Canc Netw 2019;17:855-83.

2. Jordan T, Mastnak DM, Palamar N, et al. Nutritional Therapy for Patients with Esophageal Cancer. Nutr Cancer 2018;70:23-9.

3. Kanekiyo S, Takeda S, Iida M, et al. Efficacy of perioperative immunonutrition in esophageal cancer 
patients undergoing esophagectomy. Nutrition 2019;59:96-102.

4. Álvarez-Sarrado E, Mingol Navarro F, J Rosellón R, et al. Feeding Jejunostomy after esophagectomy cannot be routinely recommended. Analysis of nutritional benefits and catheter-related complications. Am J Surg 2019;217:114-20.

5. Akiyama Y, Iwaya T, Endo F, et al. Evaluation of the need for routine feeding jejunostomy for enteral nutrition after esophagectomy. J Thorac Dis 2018;10:6854-62.

6. Koterazawa Y, Oshikiri T, Hasegawa H, et al. Routine placement of feeding jejunostomy tube during esophagectomy increases postoperative complications and does not improve postoperative malnutrition. Dis Esophagus 2020;33:doz021.

7. Al-Temimi MH, Dyurgerova AM, Kidon M, et al. Feeding Jejunostomy Tube Placed during Esophagectomy: Is There an Effect on Postoperative Outcomes? Perm J 2019;23:18-210.

8. Arif A, Bangash AN, Gul A, et al. Frequency of complications following trans hiatal esophagectomy for esophageal carcinoma with or without feeding jejunostomy. J Postgrad Med Inst 2018;32:70-5.

9. Kitagawa H, Namikawa T, Iwabu J, et al. Bowel obstruction associated with a feeding jejunostomy and its association to weight loss after thoracoscopic esophagectomy. BMC Gastroenterol 2019;19:104.

10. Wani ML, Ahangar AG, Lone GN, et al. Feeding jejunostomy: does the benefit overweight the risk (a retrospective study from a single centre). Int J Surg 2010;8:387-90.

11. Yagi M, Hashimoto T, Nezuka H, et al. Complications associated with enteral nutrition using catheter jejunostomy after esophagectomy. Surg Today 1999;29:214-8.

12. Klevebro F, Johar A, Lagergren J, et al. Outcomes of nutritional jejunostomy in the curative treatment of esophageal cancer. Dis Esophagus 2019;32:doy113.

13. Kroese TE, Tapias L, Olive JK, et al. Routine intraoperative jejunostomy placement and minimally invasive oesophagectomy: An unnecessary step? Eur J Cardiothorac Surg 2019;56:746-53.

14. Gong L, Yan B, Chen Y, et al. Alternative method for jejunostomy in Ivor-Lewis esophagectomy. Thorac Cancer 2015;6:296-302.

15. Scarpa $M$, Cavallin F, Noaro G, et al. Impact of jejunostomy during esophagectomy for cancer on health related quality of life. Chin J Cancer Res 2014;26:678-84.
16. Huang K, Wu B, Ding X, et al. Post-esophagectomy tube feeding: a retrospective comparison of jejunostomy and a novel gastrostomy feeding approach. PLoS One 2014;9:e89190.

17. Konishi T, Shiozaki A, Fujiwara H, et al. Comparison of Feeding Jejunostomy via Gastric Tube Versus Jejunum After Esophageal Cancer Surgery. Anticancer Res 2018;38:4941-5.

18. Kawai R, Abe T, Uemura N, et al. Feeding catheter gastrostomy with the round ligament of the liver prevents mechanical bowel obstruction after esophagectomy. Dis Esophagus 2017;30:1-8.

19. Elshaer M, Gravante G, White J, et al. Routes of early enteral nutrition following oesophagectomy. Ann R Coll Surg Engl 2016;98:461-7.

20. Takesue T, Takeuchi H, Ogura M, et al. A Prospective Randomized Trial of Enteral Nutrition After Thoracoscopic Esophagectomy for Esophageal Cancer. Ann Surg Oncol 2015;22 Suppl 3:S802-9.

21. Rajabi Mashhadi MT, Bagheri R, Ghayour-Mobarhan M, et al. Early Post Operative Enteral Versus Parenteral Feeding after Esophageal Cancer Surgery. Iran J Otorhinolaryngol 2015;27:331-6.

22. Oya H, Koike M, Iwata N, et al. Feeding duodenostomy decreases the incidence of mechanical obstruction after radical esophageal cancer surgery. World J Surg 2015;39:1105-10.

23. Cao S, Zhao G, Cui J, et al. Fast-track rehabilitation program and conventional care after esophagectomy: a retrospective controlled cohort study. Support Care Cancer 2013;21:707-714.

24. Fenton JR, Bergeron EJ, Coello M, et al. Feeding jejunostomy tubes placed during esophagectomy: are they necessary? Ann Thorac Surg 2011;92:504-11.

25. Lidder P, Flanagan D, Fleming S, et al. Combining enteral with parenteral nutrition to improve postoperative glucose control. Br J Nutr 2010;103:1635-41.

26. Hirahara N, Tajima Y, Fujii Y, et al. Preoperative Prognostic Nutritional Index Predicts Long-Term Surgical Outcomes in Patients with Esophageal Squamous Cell Carcinoma. World J Surg 2018;42:2199-208.

27. Quyen TC, Angkatavanich J, Thuan TV, et al. Nutrition assessment and its relationship with performance and Glasgow prognostic scores in Vietnamese patients with esophageal cancer. Asia Pac J Clin Nutr 2017;26:49-58.

28. Steenhagen E, van Vulpen JK, van Hillegersberg R, et al. Nutrition in peri-operative esophageal cancer 
management. Expert Rev Gastroenterol Hepatol 2017;11:663-72.

29. Mahmoodzadeh H, Shoar S, Sirati F, et al. Early initiation

Cite this article as: Shen X, Zhuo ZG, Li G, Alai GH, Song $\mathrm{TN}, \mathrm{Xu}$ ZJ, Yao P, Lin YD. Is the routine placement of a feeding jejunostomy during esophagectomy worthwhile?a systematic review and meta-analysis. Ann Palliat Med 2021;10(4):4232-4241. doi: 10.21037/apm-20-2519 of oral feeding following upper gastrointestinal tumor surgery: a randomized controlled trial. Surg Today 2015;45:203-8. 